\title{
Another freak of nature? Dysphagia hemangioma
}

\author{
Anthony W. Kim, MD \\ From the Section of Thoracic Surgery, Yale School of Medicine, New Haven, Conn. \\ Disclosures: Author has nothing to disclose with regard to commercial support. \\ Received for publication May 4, 2016; accepted for publication May 6, 2016; available ahead of print July 14, \\ 2016. \\ Address for reprints: Anthony W. Kim, MD, Section of Thoracic Surgery, Yale School of Medicine, 330 Cedar St, \\ BB 205, New Haven, CT 06520 (E-mail: anthony.kim@yale.edu). \\ J Thorac Cardiovasc Surg 2016;152:e63 \\ $0022-5223 / \$ 36.00$ \\ Copyright (C) 2016 by The American Association for Thoracic Surgery \\ http://dx.doi.org/10.1016/j.jtcvs.2016.05.033
}

Managing disease processes that occur with rare frequency poses a unique set of diagnostic and treatment challenges that are rooted in the paucity of experience from which surgeons can draw. Esophageal hemangiomas are representative of these issues. On the basis of older data that have yet to be supplanted and that include autopsy studies, the incidence of esophageal hemangiomas can range from $0.009 \%$ to $0.04 \%$ depending on how the denominator is defined. ${ }^{1}$ This range does not lend itself to a wealth of clinical experience to establish tried and true pathways in managing esophageal hemangiomas.

The case of the hemangioma ${ }^{2}$ in the cervical esophagus reported in this month's Journal highlights some additionally unique elements to an already rare condition. The sheer appearance of the lesion as demonstrated in the authors' preoperative and intraoperative imaging is impressive. Despite its size, the progression of dysphagia may have been only gradual because of the compressible nature of the lesion and the ability of their patient to adapt as they suggest others have adapted historically. This type of presentation in the context of a previously identified mass with no evidence of strictures or motility disorders issues certainly provides credence to defining a subset of unique patients with a less severe form of dysphagia. Since the original description of David Bayford's case presented in 1787 at the meeting of the Medical Society of London, dysphagia lusoria (originally described as lusoria naturae, or "freak of nature") has been a well-described symptom synonymous with aortic arch vessel anomalies, namely, an aberrant right subclavian artery coursing behind the esophagus. ${ }^{3}$ It certainly is not unfathomable to consider that a more indolent form of dysphagia from a compressible submucosal mass could be used to describe the unique group of patients with esophageal hemangiomas. The value of delineating this subset remains to be determined, but with a growing experience with esophageal hemangiomas there is sure to be some benefit.

\section{References} Surg Engl. 1979;61:63-7. 2007; $133: 1665-7$

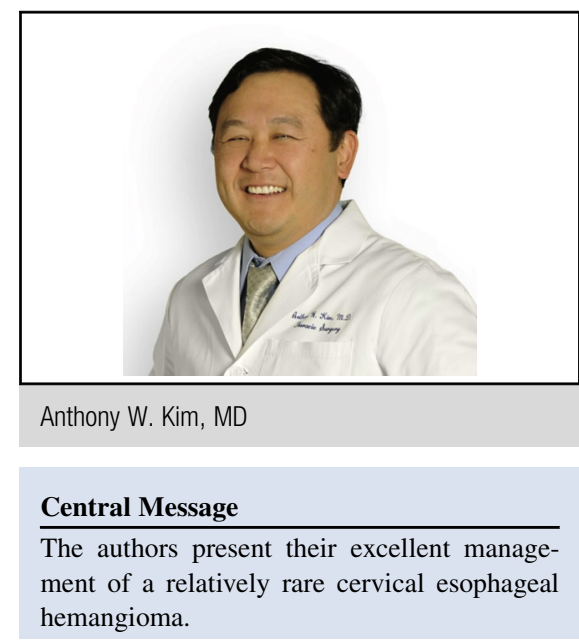

See Article page e59.

One interesting diagnostic adjunct that the esophageal hemangiomectomists of the future may want to consider is an endoscopic ultrasound. Among other advantages, ultrasonography could better characterize this entity and aid in determining the optimal surgical approach. Both minimally and maximally invasive approaches in the form of endoscopic therapies and esophageal resections for esophageal hemangiomas have been described. ${ }^{4,5}$ At the minimum though, ultrasonographic data at least could provide greater detail regarding the compressive nature of these lesions and predict dysphagia that is only slowly progressive.

The authors ${ }^{2}$ who managed this unique case are to be commended for approaching their case in a thoughtful and adept manner. The careful workup of their patient's dysphagia hemangioma ultimately served them well and resulted in a technically beautiful outcome.

1. Govoni AF. Hemangiomas of the esophagus. Gastrointest Radiol. 1982;7:113-7.

2. Santamaria-Barria JA, Banki F, Rajendran S, Floyd C. Hemangioma of the cervical esophagus: a rare case of dysphagia mimicking a large esophageal polyp on endoscopy. J Thorac Cardiovasc Surg. 2016;152:e59-61.

3. Asherson N, Bayford D. His syndrome and sign of dysphagia lusoria. Ann R Coll

4. Kim AW, Korst RJ, Port JL, Altorki NK, Lee PC. Giant cavernous hemangioma of the distal esophagus treated with esophagectomy. I Thorac Cardiovasc Surg.

5. Cantero D, Yoshida T, Ito T, Suzumi M, Tada M, Okita K. Esophageal hemangioma: endoscopic diagnosis and treatment. Endoscopy. 1994;26:250-3. 